\title{
Innovation Points Analysis of Human Resource Management of International Brand Hotel
}

\author{
Jie Lin \\ Hainan College of Economics and Business, Haikou, 571127, China
}

Keywords: International Brand Hotel. Innovation Points. Human Resource Management

\begin{abstract}
The staff service level of international brand hotel directly affects its economic benefits. Therefore, hotel's human resource management innovation is the only way which must be passed to improve its economic benefits. However, there are still human resource management problems in human resource planning and institutional adjustment of domestic star hotels, which do not help to improve their service level and seriously impede the economic benefits improvement of domestic hotels. With the deepening of reform and opening up, more international brand hotels enter China. China can learn from the human resource management model of international brand hotel to improve its staff service level.
\end{abstract}

\section{Introduction}

With the continuous development of national economy, the service industry has flourished. In the service sector, hotel industry has more rapid development. Under the influence of development of modern transportation, people need to contact hotel anywhere. The hotel industry belongs to service industry, whose staff service level and awareness directly affect its economic benefits. To improve staff awareness of service and concept, human resource management innovation must be strengthened. Mobilize the service enthusiasm of the staff and inspire their greatest potentiality through effective human resource management.

With the deepening and establishment of reform and opening up, a number of international brand hotels enter the domestic market. The brand, management and capital, etc. of international brand hotels in human resource management surpass domestic hotels. International brand hotel has a complete set of standardized management system and standard can be developed in human resource management. The international brand hotels can provide high remuneration as well as system training offering more promotion opportunities for staff. The essence of international brand hotel in human resource management is to ensure the wishes of personal development and career planning of staff.

\section{Status of Human Resource Management of Domestic Hotel}

\section{Booming of hotel industry.}

There are more and more new hotels across the country, and substantial increase in the demand for human resource in hotel industry. Especially the entering of international brand hotels and development of economical chain hotels require large human resource demand. The other reason for large demand is that a lot of people who are affected by China's traditional culture and can not update cognition to the nature of hotel do not want to work in hotel industry. Joint action of two aspects lead to the current huge demand for human resource of domestic hotels.

Unstable hotel human resource.

At present, many domestic hotels adopt incorrect approach on human resource management. In order to obtain high-quality hotel management and service staff, many hotels have spend a large amount of money to attract outstanding job-hopping personnel. Meanwhile, the job-hopping personnel will be entrusted with an important post who will block the promotion opportunities for original staff, which will form a "vicious circle " of human resource in the hotel industry. 


\section{No scientific and rational human resource planning of domestic hotel.}

At present, many managers and owners of hotel have seldom studied systematic human resource planning. Many managers have deviation understanding for human resource management planning, who consider that human resource planning does not keep up with changes. Therefore, many hotels are lack of human resource planning, which will cause chaos of human resource management and mistakes of human resource management strategy. In the end, many hotels have directly implemented the "buy policy" for management personnel, and such human resource management strategy not only fails to reduce the cost of management training, while also results in frequent changes of hotel staff, which is not conducive to the cultivation of hotel culture and have high outflow of talents. To win in the market competition, hotel must improve their staff's service capabilities and service level, while the improvement of service capabilities and level relies on the impact of culture and positioning of the hotel. Frequent changes of management personnel will only make chaos of hotel culture and positioning, which is not conducive to the establishment of hotel brand.

\section{Lack of Scientific Standardized Evaluation System of Human Resource Management}

Many domestic hotels do not pay attention to the work quality evaluation for staff, which main use evaluation checklists method for staff's evaluation. This evaluation method can not attract staff's interest, which can not reach the effect to promote staff's advancement. Secondly, the evaluation criteria is not scientific enough and evaluation system is imperfect. Many hotels have ignored the market conditions and developed high evaluation standards for staff, which lead directly to the outflow of talents and decline of staff's satisfaction.

\section{Innovation Points of Human Resource Management of International Brand Hotel}

With the deepening of reform and opening up, more and more international companies enter the domestic market, which bring competitive pressure to domestic enterprises as well as advanced management experience and technology. If domestic enterprises, especially domestic hotel industry want to compete successfully in the market, they must attach importance to human resource management innovation of the hotel. The human resource management innovation can be launched through learning advanced human resource ideas and concepts from international brand hotel and combining with the actual situation of their own. In terms of human resource management innovation of international brand hotel, there are main points below.

\section{Ways Innovation of HR Source}

In terms of hotel industry which belongs to service industry, its core on survival and development is the hotel services. A hotel can only promote economic benefits through high level of hotel services, while the hotel's high level of service attitude is reflected by the hotel staff. Thus, staff training is one of the key points of international brand hotel's work. International brand hotel has a continuous dynamic work in human resource training.

First, staff training must consistent with development direction, economic foundation and strength planning of the hotel. Human resource training must be based on the hotel's development, and also serves for hotel's development. Due to strong economic strength, international brand hotel generally spend a lot of money on staff training. The hotel in average economic strength can focus on staff training for key position. Never launch blind training activities, which will bring greater economic pressure to the hotel. International brand hotel adopts popularization training, which should not affect normal operation of the hotel. International brand hotel truly has shortest time and minimal impact in human resource training.

Second, in terms of staff training purposes, international brand hotel pays great attention to the match of staff training, human resource structure of its own and trends of talents, through which the hotel can reasonably allocate positions according to its needs and personal wishes.

Finally, the international brand hotel also pays attention to guiding the hotel staff to establish development intention consistent with goal of the hotel in the process of training, which can fully exploit the personal potentiality of staff and improve personal qualities. In addition, it also focuses on skills training for staff to pave the way for construction of hotel culture. 


\section{Incentive Mechanism Innovation}

Managers of International brand hotel attach great importance to incentive mechanism. The hotel only has a good incentive mechanism which can further mobilize the enthusiasm of the staff. The implementation of hotel incentives depends on high-quality managers. Therefore, international brand hotel will employ a variety of effective ways to improve the management level of managers. At the same time, pay attention to their psychological reactions after receiving incentives, in order to ensure effectiveness of incentives.

1). Through related demand theory, we can clearly know that person's demand can be divided into certain levels. Therefore, targeted innovative incentive mechanisms should be conducted based on the hierarchy of needs. According to different human hierarchy of needs, international brand hotel adopts different incentives, thus greatly improves the motivation of staff in international brand hotel. International brand hotel adopts the incentive mechanism combining a variety of effective incentives to motivate staff, in order to meet their needs in different levels. In simple terms, the grass-roots service staff give emphasis on how much salary they can be gained. Therefore, the main incentive is material incentives. While first-line managers give more concerns about the prospects for their development compared with the grass-roots service staff. Therefore, the main incentive is progress incentives. Whatever incentives are adopted, its ultimate aim is to stabilize the hotel staff for cultivation of the hotel culture.

2). According to different effects, incentives can be divided into short-term incentives and long-term incentives. International brand hotel often combines short-term incentives and long-term incentives. Carry out short-term incentives can make staff continue to maintain energetic work attitude when the task becomes large. Hotels in peak passenger flow period is a test. If staff in the peak passenger flow period can continue to maintain a good attitude, or further improve service level, these will give customers a good impression. The hotel may can carry out short-term incentives for staff under specific circumstances in order to improve its economic benefits. The long-term incentives can bring long-term benefits for the hotel. Only long-term incentives can attract better talents and maintain talents. International brand hotel often achieve positive alternation of human resource through the introduction of scientific competition mechanism, and optimize the structure of hotel staff through scientific evaluation mechanism.

3). Build favorable hotel culture. Whether the international brand hotel can attract new staff while stabilize the original staff, which relies on favorable hotel culture of international brand hotel. The favorable hotel culture tends to improve loyalty of staff in work, improve internal cohesion as well as show spirit of the hotel. Hotel culture has certain extent psychological impact on staff to regulate their behaviors. The progressive hotel culture itself is the spiritual motivation of the staff, improving their sense of belonging and loyalty.

\section{Remuneration Structure of Human resource and Position Management Innovation}

Remuneration management is one of the key points of human resource management. The remuneration of hotel more than just reflects personal values, as well as an important aspect to attract the hotel staff. Remuneration of staff determines their consumption capacity as ell as affects their development space. However, the level of remuneration must also be carried out based on their capabilities. Relying solely on high salaries to retain staff will inevitably lead to the hotel's financial burden. The remuneration structure of human resource innovation can make international brand hotel give remuneration which can satisfy staff expectations within the hotel capacity. International brand hotel can ensure fair remuneration through the development of implementation of remuneration management policy, what's more, pay attention to the use of spiritual motivation during the remuneration structure innovation salary structure in order to improve staff loyalty.

International brand hotel adopts job rotation mechanism in job management; job rotation mechanism is based on enterprise needs and personal wishes, launch assessment through performance, and is achieved through personal evaluation mechanism. Job rotation mechanism can effectively adjust the current positions not suitable for current staff and burnout staff. These staff will be adjusted to fit their jobs, which can play the best use of staff and greatly mobilize their enthusiasm. It is also conducive to the overall development of the hotel staff and staff development in high 
comprehensive ability. Moreover, job rotation mechanism allows staff have more exchanges with colleagues in other departments to broaden their horizons.

\section{Building of Growth Environment of Human resource}

Human resource management gives priority to "people issues". The hotel's modern human resource management must insist on the core of understanding human nature and respecting human nature to achieve "people-oriented". Human resource management in the hotel should handle relationships between itself and staff, the staff and the work, as well as the staff and hotel environment. Human resource management needs to take some time to accumulate knowledge, experience and ability. It is necessary to build favorable environment for the growth of human resource to play properly the role of human resource management. The international brand hotel attaches great importance to the adoption of staff rational proposals in human resource management, and grass-roots service staff will exchange face to face with customers to fully understand customers' needs. Suggestions of grass-roots staff are the very important reference for improvement of hotel's working. Meanwhile, the international brand hotel considers that is an important image representative of the hotel through staff confront customers. Staff satisfaction with the hotel will greatly affect their work attitude. One hotel staff not satisfied with the work must not show good spirit to the customer, neither provide good service, which makes the hotel's image and brand compromise in customers' impression. Thus, building favorable environment for the growth of human resource is a prerequisite for human resource management innovation.

\section{Conclusion}

In summary, international brand hotel has a lot of valuable experience in human resource management innovation which can be learned by domestic hotels. Domestic hotels must pay attention to human resource management innovation when conduct brand strategy development. It can learn essence from human resource management of international brand hotel to stabilize the hotel human resource, improve human resource management effect, retain talents and attract talents. Cultivate the hotel culture on the basis of stability in human resource. While strengthening human resource management, hotels should pay attention to build favorable human resource environment in order to meet the human resource management. The hotel industry can achieve better development only based on a good foundation in human resource management.

\section{References}

[1] Li Peiqing, Liangbing; Hotel Financial Management Mode Selection of Media Group - Chu Tian (GDH) International Hotel as the example, News Sentinel, 2011, (08).

[2] Mao Huilin; Analysis and Solutions Hotel Staff Outflow, Journal of Management, 2011, (05).

[3] liufang, Gao Jianlai; Brand Management: The Key to Healthy Sustainable Development of Enterprises, Journal of Economy and Technology Cooperation, 2009, (15).

[4] Zhang Wenhua; Human Resources Management Strategy Study of Economy Hotel in Wuhan, Management and Science and Technology of Small and Medium-sized Enterprises (Third Ten-day), 2012, (04).

[5] Li Mingyu; Human Resource Development Strategies Study of Economy Hotel in Shenyang Based on SWOT Analysis Method, Journal of Shenyang College of Education, 2009, (05) .

[6] Chenyong; Incentive Status Analysis of Trustees of Hotel Management- Based on In-depth Interviews and Questionnaires to 52 International Brand Hotels, Tourism Sciences, 2008, (01) . 